\title{
Association of Backpack Loads and Wearing Time with Musculoskeletal Disorders in School Children of Wah Cant Pakistan: Correlational study
}

\section{Rabia Sundas}

Riphah International University Islamic International Medical College

Misbah Ghous ( $\nabla$ drmisbahghous@gmail.com)

Riphah International University Islamic International Medical College https://orcid.org/0000-00015280-7488

\section{Shadab Sehar}

Riphah International University Islamic International Medical College

\section{Research article}

Keywords: Backpacks, load, wearing time, School children, Pain, Dysfunction, musculoskeletal

Posted Date: September 9th, 2019

DOI: https://doi.org/10.21203/rs.2.14212/v1

License: (a) (1) This work is licensed under a Creative Commons Attribution 4.0 International License. Read Full License 


\section{Abstract}

Background: Young children are carrying heavy bags to and from their schools. The use of backpacks increases recently because of several factors, including decreased availability of school lockers, increased homework, text books \& other belongings being carried to school. All these factors amplify backpack weight which have drastic effects on young students' musculoskeletal system.

Methods: This was a correlational study. Data collection was done between Septembers to December 2018. The inclusion criteria were healthy young boys and girls of school children, with no known history of any musculoskeletal disorder or any other deformity or pathology. Survey was done through selfstructured questionnaire and Nordic Musculoskeletal questionnaire. SPSS 21.0 was used for data analysis.

Results: A total of 1104 students were included in the study, mean age of the students was $11.90 \pm 2.2$ (range 8-15) years. There were $48.4 \%$ males while $51.6 \%$ were females. Frequency of fatigue due to heavy backpack was $61.6 \%$.Neck pain was common in $40.2 \%$ students, shoulder pain in $47.4 \%$ and the frequency of low back pain was $46.6 \%$.According to BMI $33.2 \%$ students had normal BMI and $32.6 \%$ students were very severely underweight which is an alarming situation. The correlation of bag pack weight with students $B M I$ was weak positive $(r=0.25, p<0.05)$

Conclusion: This study concluded that the frequency of musculoskeletal pain was high due to carrying heavy backpacks. Upper and low back pain were the most common type. Maximum students carry $>16 \%$ ratio of backpacks load. Wearing time of backpack was more than 10 minutes. Keywords: Backpacks, load, wearing time, School children, Pain, Dysfunction, musculoskeletal

\section{Background}

Prevalence of musculoskeletal disorders in developing world is very high due to malnutrition and imbalanced diet in young children.(1) The heavy backpack problem in young students and its correlation to different types of bad posture, as well as pain in particular parts of the back, has been an important issue over the last few years (2). Young children are developing irreversible back deformities because of the weight of the bags they carry to school (3). Half of children suffer back pain by the age of 14 and doctors are reporting a rise in cases of spinal abnormalities in pupils, including disfiguring curvatures known as scoliosis (4). Overloaded school bags that are up to double the size of those carried ten years ago are contributing to the surge, it is feared (5). Children's skeletons are still growing so carrying heavy bags can cause lasting damage to spine (6). Many students are carrying their bags on one shoulder or are increasingly carrying them on the crook of their elbow, so are placing a great strain on the spine (7). A lot of the bags being used are bulky sports bags, which are twice the size of backpacks used a decade ago (4). In developing countries like Pakistan there is no emphasis on health care of adolescent and effects of heavy loads on the back of children (8). Backpacks are commonly used by children in Pakistan and no remedial measures have been taken to solve this problem. Back 
problems are becoming an increasing issue among schoolchildren and schools no longer have adequate desk space for pupils to store heavy books (9). The use of backpacks increases recently because of several triggers, including decreased availability of school lockers, increased homework, larger text books \& other belongings being carried to school (10). All these factors amplify backpack weight. Literature confirms that postural compensations and subjective complaints due to backpack loads and wear time in schoolchildren shows that typical backpack loads create worsening postural changes due to backpack loads and time spent carrying these loads $(11,12)$. Carrying backpacks increases the risk of back pain and possibly the risk of back pathology (13). The prevalence of school children carrying heavy backpacks is extremely high. Preventive and educational activities should be implemented in this age group.(14) A study was conducted by Brewer JM et al which revealed that ergonomic mismatch had limited impact on the body discomfort. It appears that other factor such as backpack weight and time carrying may contribute more to the discomfort of students.(15) Musculoskeletal pain, fatigue and tiredness has negative effects on children's quality of life (QOL) and on their academic performances (16). This study aimed to find the association of backpack loads and wearing time with musculoskeletal disorders in school children.

\section{Methods}

This was a correlational study conducted in different government and private institutes of Wah Cant Pakistan. This study was completed in 6 months from August 2018 to January 2019. Total number of participants included in the study were $1104(n=1104)$ calculated by correlation sample size calculator.(17) Approval was obtained from the research ethical committee of Faculty of Rehabilitation and Allied health sciences, Riphah International university Islamabad. After Clearance from Research ethical Committee data was collected with informed consent from guardians, and teachers of the institutes. The inclusion criteria were healthy young boys and girls of 8-15 years old, with no known history of any musculoskeletal disorder or any other deformity or pathology. Survey was done through self-structured questionnaire and Nordic Musculoskeletal questionnaire which included demographics: Name, Age, Gender, body mass index, class grade etc. The questionnaire was filled by the researchers after inquiring all the questions from the students. Each participant took almost 5-10 minutes to complete the survey. All data collected from them was coded in order to protect the identity of the students. For data analysis SPSS 21 was used. The frequency, percentages, mean and standard deviation of different variables were calculated. Independent sample $\mathrm{T}$ test was applied to find the difference among males and females, when comparison was made between different variables. One way ANOVA was performed for the statistics of backpack weight and BMI with grades of students. For correlation analysis Spearman was used for ordinal variables and Pearson's for continuous variables. 


\section{Results}

Total 1104 school children were included in sample. The mean age of students was $11.1 \pm 2.2$ years. $534(48.4 \%)$ were male students and 570(51.6\%) females participated in this study. Out of these students 540(48.9\%) students were from public institutes and $564(51.1 \%)$ were from private institutes. The number of students who carry backpacks on both shoulder were $934(84.6 \%)$ and those who carry backpacks on one shoulder were 170(15.4\%). About 555(50.3\%) students use to walk, 268(24.3\%) use bike, 158(14.3\%) use car and $123(11.1 \%)$ use bus as a means of transport to school. The mean BMI $\left(\mathrm{kg} / \mathrm{m}^{2)}\right.$ of students was $16.7 \pm 0.49$ and mean weight $(\mathrm{kg})$ of bag packs was $5.3 \pm 2.1$. The Duration of carriage of Backpack (min) was 13.2 \pm 2.1 .

Table 1: Showed frequency, percentage, Mean \pm SD of Nordic pain questionnaire 


\begin{tabular}{|c|c|c|c|}
\hline \multicolumn{4}{|c|}{$\begin{array}{l}\text { Have you at any time during the last } 12 \text { months had trouble ( such as ache, pain, } \\
\text { discomfort, numbness)in: }\end{array}$} \\
\hline Variables & $\begin{array}{l}\text { No } \\
\text { N (\%) }\end{array}$ & $\begin{array}{l}\text { Yes } \\
\text { N (\%) }\end{array}$ & Mean \pm SD \\
\hline Neck & $660(59.8)$ & $444(40.2)$ & $1.4 \pm 0.49$ \\
\hline Shoulders & $58(52.6)$ & $523(47.4)$ & $2.23 \pm 0.4$ \\
\hline Elbows & $1072(97.1)$ & $3(3)$ & $1.1 \pm 0.36$ \\
\hline Wrist/hands & $1085(98.3)$ & $19(1.8)$ & $1.1 \pm 0.23$ \\
\hline Upper back & $590(53.4)$ & $514(46.6)$ & $1.1 \pm 0.23$ \\
\hline Lower back & $554(50.2)$ & $550(46.6)$ & $1.4 \pm 0.5$ \\
\hline One or both hip/thigh/buttocks & $1062(96.2)$ & $42(3.8)$ & $1.1 \pm 0.19$ \\
\hline One or both knees & $987(89.4)$ & $117(10.6)$ & $1.1 \pm 0.3$ \\
\hline One or both ankles/feet & $1023(92.7)$ & $81(7.3)$ & $1.1 \pm 0.26$ \\
\hline \multicolumn{4}{|c|}{ Have you had trouble during the last 7 days: } \\
\hline Neck & $741(67.1)$ & $363(32.9)$ & $1.32 \pm 0.46$ \\
\hline Shoulders & $637(57.7)$ & 467 ( 42.3) & $2.1 \pm 1.37$ \\
\hline Elbows & $1073(97.2)$ & $31(2.9)$ & $1.1 \pm 0.36$ \\
\hline Wrist/hands & $1087(98.5)$ & $17(1.6)$ & $1.1 \pm 0.23$ \\
\hline Upper back & $661(59.9)$ & $443(40.1)$ & $1.4 \pm 0.49$ \\
\hline Lower back & $603(54.6)$ & $501(45.5)$ & $1.4 \pm 0.49$ \\
\hline One or both hip/thigh/buttocks & $1066(96.6)$ & $38(3.4)$ & $1.1 \pm 0.18$ \\
\hline One or both knees & $1043(94.5)$ & $61(5.5)$ & $1.1 \pm 0.22$ \\
\hline One or both ankles/feet & 1051(95.2) & $53(4.8)$ & $1.1 \pm 0.21$ \\
\hline \multicolumn{4}{|c|}{$\begin{array}{c}\text { During the last } 12 \text { months have you been prevented from carrying out normal } \\
\text { activities(eg, job ,housework, hobbies)because of this trouble: }\end{array}$} \\
\hline Neck & $880(79.7)$ & $224(20.3)$ & $1.20 \pm 0.4$ \\
\hline Shoulders & $966(87.5)$ & $138(12.5)$ & $1.12 \pm 0.33$ \\
\hline Elbows & $1087(98.5)$ & $17(1.5)$ & $1.1 \pm 0.12$ \\
\hline Wrist/hands & $1089(98.6)$ & $15(1.4)$ & $1.1 \pm 0.11$ \\
\hline Upper back & $768(69.6)$ & $336(30.4)$ & $1.3 \pm 0.46$ \\
\hline Lower back & $596(54)$ & $508(46)$ & $1.4 \pm 0.49$ \\
\hline One or both hip/thigh/buttocks & $1093(99)$ & $11(1.0)$ & $1.1 \pm 0.3$ \\
\hline One or both knees & 1073(97.2) & $31(2.8)$ & $1.1 \pm 0.16$ \\
\hline One or both ankles/feet & $1083(98.1)$ & $21(1.9)$ & $1.1 \pm 0.13$ \\
\hline
\end{tabular}

Table 2: Showed Correlations of variables with backpack weight

\begin{tabular}{|l|c|c|}
\hline Variables & r-values & P-valves \\
\hline Age & -0.28 & $<0.001$ \\
BMI of students & 0.25 & $<0.001$ \\
Grades of student & -0.24 & $<0.001$ \\
Type of school & 0.51 & $<0.001$ \\
Duration of carriage of bag & 0.03 & $<0.001$ \\
Fatigue level & -0.43 & $<0.001$ \\
& & \\
\hline
\end{tabular}


Table 3: Independent $T$ test of different variables with gender

\begin{tabular}{|c|c|c|c|c|}
\hline Variable & Gender & $\mathbf{N}$ & Mean \pm SD & p-valve \\
\hline \multirow[b]{2}{*}{ Fatigue } & Male & 534 & $1.36 \pm 0.48$ & \multirow[t]{2}{*}{0.21} \\
\hline & female & 570 & $1.41 \pm 0.49$ & \\
\hline \multirow[t]{2}{*}{ BMI } & Male & 534 & $16.18 \pm 3.78$ & \multirow[t]{2}{*}{$<0.01$} \\
\hline & Female & 570 & $17.2 \pm 3.34$ & \\
\hline \multirow[t]{2}{*}{ Backpack weight } & Male & 534 & $5.46 \pm 2.14$ & \multirow[t]{2}{*}{$<0.01$} \\
\hline & Female & 570 & $4.91 \pm 2.1$ & \\
\hline \multirow[t]{2}{*}{ Method of carriage of bag } & Male & 534 & $1.1 \pm 0.26$ & \multirow[t]{2}{*}{$<0.01$} \\
\hline & Female & 570 & $1.22 \pm 0.41$ & \\
\hline \multirow[t]{2}{*}{ School bag heavy } & Male & 534 & $1.33 \pm 0.47$ & \multirow[t]{2}{*}{$<0.01$} \\
\hline & Female & 570 & $1.38 \pm 0.48$ & \\
\hline
\end{tabular}

Table 4: One way ANOVA for comparison of backpack weight and students BMI with grades of students

\begin{tabular}{|c|c|c|c|c|}
\hline Variable & Grade & $\mathbf{N}$ & Mean \pm SD & p-value \\
\hline \multirow{8}{*}{ Backpack weight } & 3 & 76 & $6.6 \pm 2.17$ & \multirow{8}{*}{$<0.01$} \\
\hline & 4 & 142 & $4.8 \pm 2.57$ & \\
\hline & 5 & 137 & $5.2 \pm 2.46$ & \\
\hline & 6 & 244 & $5.5 \pm 1.80$ & \\
\hline & 7 & 156 & $6.2 \pm 1.93$ & \\
\hline & 8 & 151 & $5.5 \pm 1.76$ & \\
\hline & 9 & 78 & $3.7 \pm 1.27$ & \\
\hline & 10 & 120 & $3.4 \pm 1.01$ & \\
\hline \multirow{8}{*}{ BMI of students } & 3 & 76 & $14.7 \pm 3.6$ & \multirow[t]{8}{*}{$<0.01$} \\
\hline & 4 & 142 & $14.4 \pm 3.25$ & \\
\hline & 5 & 137 & $15.3 \pm 3.49$ & \\
\hline & 6 & 244 & $16.7 \pm 3.98$ & \\
\hline & 7 & 156 & $17.8 \pm 3.16$ & \\
\hline & 8 & 151 & $18.00 \pm 3.32$ & \\
\hline & 9 & 78 & $18.1 \pm 1.64$ & \\
\hline & 10 & 120 & $18.3 \pm 2.38$ & \\
\hline
\end{tabular}


Backpacks are commonly used by students around the globe; it comes in different sizes, shapes \& color schemes. Heavy backpacks causes multiple spine deformities like disc injuries and musculoskeletal abnormalities (18). This study provided an overview about backpack loads and wearing time with musculoskeletal disorders (MSD) in school children. The prevention of back pain and other MSD's is important for student's current wellbeing and long term health. (19)

Data from 1104 school going students was taken using a self-structured and Nordic musculoskeletal questionnaire, Out of 1104 students, 534 were males and 570 were females.

The results of this study founded that an average 61.6\% (more than half of the study population) students get fatigue after carrying backpack and $38.4 \%$ students had no fatigue. Furthermore 84.6\% students carry their backpacks on both shoulders and $15.1 \%$ on one shoulder. The pain was common among $40.2 \%$ students. This study is supported by a study conducted in Karachi (Pakistan) which revealed that $43.8 \%$ students have back pack related neck pain.(8)

When the school children walk with a heavy load on their back their posture may change or complain of pain. Current study revealed that $64.2 \%$ participants have their school bags heavy. Average backpack weight was $5.1 \mathrm{~kg}$ the frequency of low back pain among students were $46.6 \%$, In comparison to a study conducted in Lahore (Pakistan) almost similar results were shown that about mean weight of bag was $6.06 \mathrm{~kg}$ and students who complained about low back pain were $18.2 \%$. (20)

Quality of life (QOL) takes into account subjective interpretations and the process in which each individual compares current life with some identified criteria. In this study students complained of pain in different regions of body which have prevented them from carrying out normal activities like hobbies, housework, sports etc (20). Among them 46\% had low back pain, 30.4\% upper back pain and 20.3\% had neck pain which affected their QOL . A similar study was published and results revealed that over $10 \%$ to $40 \%$ of adolescents have reported that their daily activities are being somewhat limited by Low back pain.(21) (22) . Perceived weight and perceived fatigue were found to be the strongest identifiers of spinal pain (23). In current study $50.3 \%$ students walk to school and $61.6 \%$ get fatigued due to heavy backpacks. A study conducted in Australia supports this study as neck pain and back pain was most common amongst adolescents. Perceived school bag load, duration of carriage and method of transport to school were associated with back and neck pain and 58\% get fatigued.(24) This study showed that mean BMI of students was $16.7 \mathrm{~kg} / \mathrm{m}^{2}$. According to BMI categories $32.6 \%$ children were very severely underweight which is alarming. The study also showed that average backpack weight was $5.1 \mathrm{~kg}$. Boys $(n=231)$ were more severely underweight than girls $(n=129)$.In comparison to a study conducted in 2014 , aimed to evaluate the load carried by students 
in primary and secondary state schools, and quantifies the percentage established between backpack weight and body mass of these young students carry every day. The age varies from 12 - 18 years old and about 59.06\% students carrying bag over 10\% of body mass, complained about pain and musculoskeletal disorders (25) (26). The limitations of this study was its cross-sectional nature which does not permit cause and effect interpretation of its findings proper postural analysis of students was not done. It is recommended that the results from this study will help in suggesting and supporting improvements to be taken regarding heavy school bag issue. The findings of this study depicted that majority of students were having low body mass which is an alarming situation and badly affected their quality of life. Bag packs weight and student's weight should be in equal ratio for good health of students. Schools should provide lockers. In this way the weight of school bag will remain in safe range.

\section{Conclusions}

The frequency of musculoskeletal pain was high due to carrying heavy backpack. Upper and low back pain were the most common type of pain. Maximum students carry $>16 \%$ ratio of backpack and wearing time of backpack was more than 10 minutes, that is an alarming issue for parents and it will cause musculoskeletal disorders in future. Way of carrying bag, heavy schedule and method of transport were the defining factors among school children

\section{Abbreviations}

BMI: Body mass Index

MSD: Musculoskeletal disorders

QOL: Quality of life

\section{Declarations}

\section{Ethics approval and consent to participate}

From Research ethical Committee of Faculty of Rehabilitation and Allied health sciences, Riphah International university Islamabad. Written informed consent for participation in the study was obtained from guardians and teachers of the institutes

\section{Consent for publication}

All authors have read and approved the manuscript and showed consent for publication.

\section{Availability of data and materials}


The datasets used and/or analyzed during the current study are available from the corresponding author on reasonable request and it is included in article.

Competing interest:

Authors showed no competing interest.

\section{Funding}

This study was not funded by any organization or institute.

\section{Authors' contributions}

Rabia Sundas: Basic concept of study, data collection, literature review, data analysis Misbah Ghous: Data analysis and interpretation. Final Drafting and manuscript writing.

Shadab Sehar: literature review, Data analysis and interpretation of data

\section{Acknowledgements}

We highly acknowledged the participating students.

\section{References}

1. George D, Nayak BS, Shetty S. Bag pack weight and musculoskeletal discomfort among school children. Nursing and Midwifery Research. 2015;11(3):97.

2. Paušić $\mathrm{J}$, Kujundžić $\mathrm{H}$, Penjak A. Possible influences of a heavy backpack on back pain syndrome in primary school children. Croatian J Educ. 2013;15(2):275-87.

3. Adegoke BO, Odole AC, Adeyinka AA. Adolescent low back pain among secondary school students in Ibadan, Nigeria. African health sciences. 2015;15(2):429-37.

4. Patil AY, Kulkarni S, Koppal S, Mathad SN. Design and analysis of backpack structure for school children using fea tool. Int J Adv Sci Eng. 2018;5:862-70.

5. Macedo RB, Coelho-e-Silva MJ, Sousa NF, Valente-dos-Santos J, Machado-Rodrigues AM, Cumming SP, et al. Quality of life, school backpack weight, and nonspecific low back pain in children and adolescents. Jornal de pediatria. 2015;91(3):263-9.

6. Andersen LB, Wedderkopp N, Leboeuf-Yde C. Association between back pain and physical fitness in adolescents. Spine. 2006;31(15):1740-4.

7. Ashtekar SV, Padhyegurjar SB, Powar JD, Siddiqui A. Intervention study for reducing schoolbag weights in two rural schools in Maharashtra. Indian journal of community medicine: official publication of Indian Association of Preventive \& Social Medicine. 2018;43(Suppl 1):S52.

8. Shahid G, Aziz K, Arif A, Fahim M. Prevalence of Musculoskeletal Pain due to Heavy Backpacks in School going Children of Karachi. Int J Phys Med Rehabil. 2018;6(471):2. 
9. Ibrahim S. Influence of the weight of a School Backpack on backache among secondary school students at Koya province, Iraq.

10. Srivastava SP, Buckshee RN. The Association of Individual Physical and Psychosocial Factors with School Bag Carriage Related Musculoskeletal Discomfort and Pain in Primary School Children. Indian Journal of Physiotherapy \& Occupational Therapy. 2017;11(4).

11. Ho D, Fetters L. Commentary on: "postural compensations and subjective complaints due to backpack loads and wear time in schoolchildren". Pediatr Phys Ther. 2013 Spring;25(1):24.

12. Zadry HR, Fithri P, Triyanti U, Meilani D. AN ERGONOMIC EVALUATION OF MOUNTAINEERING BACKPACKS. 2006.

13. Baidoo N, Quartey J, Essuman K, Armah J, Asamoah D. Association between bag weight, carrying style and low back pain and spinal curvatures among school children in Ablekuma South. Physiotherapy. 2015;101:e1243.

14. Rodriguez-Oviedo P, Ruano-Ravina A, Perez-Rios M, Garcia FB, Gomez-Fernandez D, FernandezAlonso A, et al. School children's backpacks, back pain and back pathologies. Arch Dis Child. 2012 Aug;97(8):730-2.

15. Brewer JM, Davis KG, Dunning KK, Succop PA. Does ergonomic mismatch at school impact pain in school children? Work. 2009;34(4):455-64.

16. Hasan MM, Yaqoob U, Ali SS, Siddiqui AA. Frequency of Musculoskeletal Pain and Associated Factors among Undergraduate Students. Medicine. 2018;7:131-45.

17. Natasha AA, Syukri AA, Diana MKSN, Ima-Nirwana S, Chin K-Y. The association between backpack use and low back pain among pre-university students: A pilot study. Journal of Taibah University Medical Sciences. 2018;13(2):205-9.

18. Vaghela NP, Parekh SK, Padsala D, Patel D. Effect of backpack loading on cervical and sagittal shoulder posture in standing and after dynamic activity in school going children. Journal of Family Medicine and Primary Care. 2019;8(3):1076.

19. Mohseni-Bandpei MA, Bagheri-Nesami M, Shayesteh-Azar M. Nonspecific low back pain in 5000 Iranian school-age children. Journal of Pediatric Orthopaedics. 2007;27(2):126-9.

20. Khan R, Jabeen H, Arshad HS. Neck, shoulder, and back pain with carrying heavy back packs among the spirit school children in Lahore. Age. 2016;9(12):13-6.

21. Macedo RB, Coelho MJ, Sousa NF, Valente-dos-Santos J, Machado-Rodrigues AM, Cumming SP, et al. Quality of life, school backpack weight, and nonspecific low back pain in children and adolescents. Jornal de Pediatria (Versão em Português). 2015;91(3):263-9.

22. Aprile I, Di Stasio E, Vincenzi MT, Arezzo MF, De Santis F, Mosca R, et al. The relationship between back pain and schoolbag use: a cross-sectional study of 5,318 Italian students. The Spine Journal. 2016;16(6):748-55.

23. Hadžiomerović AM, Jaganjac A, Avdic D, Pašalić A, Kaljić E, Domljan D, et al. School bags and associated back pain. Journal of Health Sciences. 2018;8(1):10-9. 
24. Haselgrove C, Straker L, Smith A, O'sullivan P, Perry M, Sloan N. Perceived school bag load, duration of carriage, and method of transport to school are associated with spinal pain in adolescents: an observational study. Australian Journal of Physiotherapy. 2008;54(3):193-200.

25. Panicker RK, Sandesh T. Prevalence of Musculoskeletal Pain in School Going Adolescents Using School Bags: A Co-relational Research. International journal of therapies and rehabilitation research. 2014;3(4):1.

26. Brzęk A, Dyrda B, Nowotny-Czupryna O, Jachacz Łopata M. Postural defects prevention programme as the exemplification of actions in the scope of health promotion in early school education-an action research perspective. New Educ Rev. 2011;24(2):194-204. 